\title{
SISTEM PENGENDALIAN DAN MEKANISME PENGELOLAAN KAS KECIL PADA RUMAH SAKIT UMUM (RSU) SHANTI GRAHA
}

\author{
Nyoman Peny Tri Wayuni \\ Jurusan Akuntansi Program Duploma III, \\ Universitas Pendidikan Ganesha,Singaraja \\ e-mail : penytriwahyuni@gmail.com
}

\begin{abstract}
Abstrak
Penelitian bertujuan untuk mengetahui sistem pengendalian dan mekanisme pengelolaan kas kecil pada rumah sakit umum (RSU) Shanti Graha. Penelitian ini merupakan penelitian deskriptif kualitatif. Subyek penelitian adalah Rumah Sakit Umum (RSU) Shanti Graha.Obyek penelitian adalah sistem pengendalian dan mekanisme pengelolaan kas kecil pada RSU Shanti Graha. Data yang digunakan adalah data kuantitatif dan data sekunder. Metode penelitian adalah dokumentasi dan wawancara.Teknik analisis yang digunakan adalah analisis deskriptif kualitatif.

Penelitian menunjukkan sistem pengendalian intern terhadap kas kecil yang dilakukan RSU Shanti Graha belum memadai. Adanya perangkapan tugas antara kasir dengan akuntansi. Pencatatan menggunakan metode fluktuasi yang menyebabkan catatan akuntansinya tidak dapat direkonsiliasi dengan rekening koran bank secara periodik serta folmulir yang digunakan masih kurang lengkap. Mekanisme pengelolaan kas kecil RSU Shanti Graha belum ada pengelolaan yang mengkhusus melainkan menggunakan metode urgen yaitu metode yang lebih mendahulukan kebutuhan yang mendesak dibandingkan kebutuhan yang bisa ditunda agar pengeluaran dana kas kecil lebih efisien.

Kata kunci : sistem pengendalian, pengelolaan kas kecil
\end{abstract}

\begin{abstract}
Absract
The purpose of this research is to know the control system and cash management mechanism in public hospital (RSU) Shanti Graha. This research is a qualitative descriptive research.

The subject of this research is Rumah Sakit Umum (RSU) Shanti Graha. Obyect this research is a Sistem Pengendalian dan Mekanisme Pengelolaan Kas Kecil at Rumah Sakit Umum (RSU) Shanti Graha. The data type used is quantitative data. The data source used is Data sekunder. Method of collection data is the documentation and interviews. The analysis technique used is descriptive qualitative analysis.

The results of this study indicate that the Sistem Pengendalian Rumah Sakit Umum (RSU) Shanti Graha is not adequate. Where still there is a duty between the cashier function with the accounting function. Then in the recording system is still using the method of fluctuations that cause accounting records can not be reconciled with bank account bank periodically and folmulir used is still not complete. Mekanisme Pengelolaan Kas Kecil at Rumah Sakit Umum (RSU) Shanti Graha is not yet special management but only using urgent method which is a method that prioritizes the urgent need compared to the need that can be postponed, with the aim that the expense of small cash fund more efficient.
\end{abstract}

Keywords: control system, small cash management 


\section{Pendahuluan}

Indonesia sebagai Negara yang sedang berkembang dengan penuh rasa optimis berusaha untuk semakin meningkatkan diri dijajaran ekonomi dunia. Sistem pengendalian pada perusahaan dilakukan untuk menjaga kekayaan perusahaan, memeriksa kebenaran dan ketelitian data akuntansi serta meningkatkan efisiensi operasi perusahaan serta mendorong dipatuhinya kebijakan dari manajemen. Salah satu komponen yang perlu diterapkan dalam sistem pengendalian adalah kas. Menurut Ni Luh Gede Erni Sulindawati pada bukunya "Manajemen Keuangan" menjelaskan bahwa kas adalah salah satu unsur modal kerja yang paling tinggi tingkat likuiditasnya. Kas juga merupakan aktiva paling lancar dan sering mengalami perubahan.Oleh karena itu, adanya pengendalian yang memadai terhadap kas sangat diperlukan mengingat sifat kas yang mudah dipindah tangankan serta tidak dapat dibuktikan kepemilikannya . Rumah Sakit Umum Shanti Graha merupakan rumah sakit pertama terbesar di daerah buleleng barat. PT. Mekar Shanti Graha sebagai pemilik RSU Shanti Graha memiliki komitmen untuk menjadi rumah sakit pilihan utama masyarakat khususnya masyarakat Buleleng Barat. Kas yang ada di perusahaan terdiri dari kas besar dan kas kecil. Kas besar di tangani oleh kasir yang bertugas menerima pembayaran dari pelanggan yang melakukan pembayaran secara tunai serta mengeluarkan cek untuk membayar pengeluaran dalam jumlah yang besar.

Sedangkan kas kecil disediakan untuk membiayai pengeluaran-pengeluaran dengan jumlah relatif kecil yang tidak ekonomis dibayar dengan cek. Metode pencatatan kas kecil yang diterapkan pada RSU Shanti Graha adalah metode fluktuasi, dimana setiap pengeluaran kas akan langsung dicatat dan dijurnal oleh pemegang kas kecil sebagai penanggung jawab, sehingga saldo dana kas kecil akan selalu berfluktuasi atau berubahubah dari waktu ke waktu sesuai dengan kebutuhan. Besarnya dana kas kecil yang dianggarkan untuk operasi tidak ditentukan mengingat pengisian dana kas kecil tergantung dengan keperluan yang dibutuhkan. Sehingga jika tidak ada keperluan, dana kas kecil tidak akan dilakukan pengisian tetapi tetap terdapat sisa saldonya. Pemegang dana kas kecil pada RSU Shanti Graha juga merangkap untuk melakukan fungsi akuntansi. Hal tersebut akan menyulitkan dalam pengawasan terhadap pengendalian intern kas kecil. Bertitik tolak dari hal tersebut, maka penulis tertarik untuk melakukan penelitian yang berjudul "Sistem Pengendalian dan Mekanisme Pengelolaan Kas Kecil pada Rumah Sakit Umum Shanti Graha."

\section{Metode Penelitian}

Penelitian ini dibuat untuk memberikan kejelasan yang berkaitan dengan pemilihan pendekatan yang akan digunakan dalam penelitian, untuk memperoleh informasi mengenai sistem pengendalian dan mekanisme pengelolaan kas kecil. Adapun sistematika yang dilakukan dalam penelitian ini yaitu menentukan lokasi penelitian.Penelitian ini di awali dengan melakukan observasi awal pada lokasi penelitian yaitu RSU Shanti Graha Desa Sulanyah Kecamatan Seririt, yang bertujuan untuk mendapatkan gambaran mengenai kegiatan operasional RSU Shanti Graha. Melalui proses observasi awal, maka akan ditetapkan rumusan masalah. Untuk menjawab rumusan masalah tersebut maka diperlukan kajian pustaka untuk dikaji secara rinci yang melandasi penelitian ini.Setelah kajian pustaka telah dipaparkan maka selanjutnya akan dilakukan pengumpulan data sekunder. Metode pengumpulan data yang dilakukan untuk memperoleh data yaitu dengan menggunakan metode dokumentasi dan wawancara.Jika pengumpulan data sudah selesai dan sudah lengkap, maka tahap selanjutnya adalah mengolah data. Data yang diolah tersebut kemudian dianalisis dengan menggunakan deskriptif kualitatif meliputi laporan arus kas , rekapan kas kecil dan beberapa dokumen lainnya yang berhubungan dengan penelitian. 


\section{Hasil dan Pembahasan}

Dana kas kecil pada RSU Shanti Graha dipegang oleh seorang kasir kas kecil yang juga difungsikan untuk melakukan fungsi akuntansi terhadap semua transaksi kas kecil. Dana kas kecil disediakan khusus untuk membiayai operasional perusahaan baik bersifat rutin maupun insidentil. Dana kas kecil pada RSU Shanti Graha dipergunakan untuk keperluan biaya operasi sehari-hari sebesar Rp.1.000.000,00 sampai dengan Rp. 20.000.000,00 yang biasanya digunakan untuk biaya dokumen perusahaan, perlengkapan kantor, bayar hutang jangka pendek dan lain sebagainya. Pada awal bulan dan akhir bulan, pengisian dana kas kecil mencapai Rp. 150.000.000,00 sampai dengan 180.000.000,00 yang dipergunakan untuk keperluan biaya gaji Dokter dan bayar Jasa Dokter. Besarnya dana kas kecil yang dianggarkan untuk operasi tidak ditentukan mengingat pengisian dana kas kecil tergantung dengan keperluan yang dibutuhkan. Sehingga jika tidak ada keperluan, dana kas kecil tidak akan dilakukan pengisian tetapi tetap terdapat sisa saldonya. Selanjutnya mengenai dana kas kecil ini akan dibahas sebagai berikut :

1) Metode Pencatatan yang Digunakan RSU Shanti Graha

Metode pencatatan dana kas kecil pada RSU Shanti Graha dijalankan dengan menggunakan metode fluktuasi dan dipegang oleh seorang kasir kas kecil yang sekaligus merangkap untuk melakukan fungsi akuntansi terhadap setiap transaksi kas kecil. Dengan ditetapkannya penggunaan metode fluktuasi, maka setiap terjadi transaksi akan langsung dicatat sehingga akan merubah saldo rekening dana kas kecil.

\section{2) Pembentukan Dana Kas Kecil}

Pembentukan dana kas kecil pada RSU Shanti graha dianggarkan sebesar Rp. 1.000.000,00 sampai dengan Rp. 20.000.000,00 untuk biaya operasi sehari-hari yang bersifat rutin. Sedangkan pada bulan tertentu seperti awal bulan atau akhir bulan pembentukan dana kas kecil dianggarkan sebesar Rp. 150.000.000,00 sampai Rp. $180.000 .000,00$ yang digunakan untuk keperluan yang bersifat insidentil.

\section{3) Pengeluaran Dana Kas Kecil}

Folmulir yang digunakan untuk pengeluaran dana kas kecil pada RSU Shanti Graha adalah Bukti Pengeluaran Kas. Selain untuk pengeluaran dana kas kecil, bukti ini juga digunakan sebagai dasar untuk mengeluarkan cek oleh kasir kas besar.

4) Pengisian Kembali Dana Kas Kecil

Pengisian kembali dana kas kecil RSU Shanti Graha dilakukan jika terjadi keperluan, misalnya ada karyawan yang melakukan pengajuan mengenai transaksi yang menyangkut kas kecil, jika dana kas kecil yang ada di kasir kas kecil habis atau tidak mencukupi maka akan dilakukan pengisian kembali dana kas kecil. Sehingga pengisian kembali yang dilakukan tidak ada batasan melainkan sesuai dengan keperluan atau sejumlah transaksi yang terjadi. Jadi jika tidak ada keperluan, dana kas kecil tidak akan dilakukan pengisian tetapi tetap terdapat sisa saldonya.

5) Selisih Kas

Di dalam pencatatan kas kecil RSU Shanti Graha dapat terjadi adanya selisih antara pencatatan kas kecil pada buku kas kecil dengan bukti-bukti pembayaran yang diterima. Adanya selisih ini disebabkan oleh kurang telitinya kasir kas kecil dalam melakukan pencatatan seperti lupa mencatat transaksi atau pengeluran yang terjadi pada buku kacil padahal bukti atau notanya sudah ada dan kesalahan mencatat. Adanya selisih tersebut tidak bisa dihindari, untuk itu jika lupa mencatat dan buktinya masih ada masih bisa dicatat 
kembali, namun jika terjadi kesalahan mencatat maka selisih tersebut akan ditutupi dengan uang pribadi milik kasir kas kecil yang bertugas melakukan pencatatan pada buku kas kecil.

6) Penyajian di Neraca

Pada RSU Shanti Graha, penyajian kas kecil di neraca digabungkan dengan penyajian kas besar dengan nama perkiraan Kas, sehingga setiap akhir periode saldo kas kecil dan kas besar dijumlahkan untuk mendapatkan saldo perkiraan kas.

Berdasarkan data dari uraian mengenai pengendalian dana kas kecil pada RSU Shanti Graha, maka berikut ini akan diuraikan mengenai analisis terhadap pengendalian dana kas kecil berdasarkan dengan teori mengenai pengendalian intern kas kecil yang terdapat pada kajian teori yaitu :

1. Adanya pemisahan tanggung jawab fungsional yang tegas

Pada RSU Shanti Graha tidak terdapat adanya pemisahan tanggung jawab fungsional secara tegas, seperti pada kasir kas kecil RSU Shanti Graha yang juga bertugas untuk melakukan pencatatan atas seluruh transaksi dana kas kecil yang dipeganya. Karena sesuai dengan sifatnya yang mudah dipindah tangankan dan tidak dapat dibuktikan kepemilikannya maka dana kas kecil tersebut sangat mudah untuk digelapkan. Adanya perangkapan tugas ini akan semakin membuka peluang terjadinya kecurangan-kecurangan yang bisa dilakukan oleh kasir, sebab dari rangkaian awal sampai akhir transaksi dikerjakan sendiri. Hal ini mencermikan bahwa pada RSU Shanti Graha tidak adanya suatu pengendalian yang memadai tehadap kas kecil.

\section{Sistem pencatatan}

Dilihat dari pemaparan mengenai pencatatan kas kecil yang terdapat pada kajian teori, sistem pencatatan kas kecil harus diselenggarakan menggunakan metode imprest system. Pada RSU Shanti Graha menetapkan untuk menggunakan metode fluktuasi dalam mengelola dana kas kecilnya. Dengan menggunakan metode ini dimana setiap terjadi pengeluaran dana kas kecil akan langsung dicatat dan dijurnal dengan mendebet rekening biaya. Sistem penyelenggaraan kas kecil ini tidak menciptakan pengendalian intern yang baik terhadap kas perusahaan, karena catatan akuntansi kas perusahaan tidak dapat direkonsiliasi dengan rekening Koran bank yang secara periodik diterima dari bank.

\section{Dokumen yang digunakan}

Pada RSU Shanti Graha belum menggunakan folmulir Permintaan Pengeluaran Dana Kas Kecil dan Permintaan Pengisian Kembali Dana Kas Kecil, dimana folmulir yang digunakan pada RSU Shanti Graha pada saat pengeluaran dana kas kecil adalah Bukti Pengeluaran Kas yang menjadi bukti bahwa sudah dikeluarkannya dana kas kecil tersebut dan Bukti Penerimaan Kas digunakan saat pengisian dana kas kecil dimana folmulir tersebut menjadi bukti bahwa sudah diterimanya dana kas kecil oleh kasir.

\section{Praktek yang sehat}

Sebaiknya untuk mendapat pengendalian yang baik terhadap kas perusahaan, maka seluruh pengeluaran kas dilakukan menggunakan cek, sehingga kebenaran pencatatan pembayaran yang dilakukan oleh perusahaan dapat dibandingkan dengan rekening koran bank, dan untuk pengeluaran uang tunai dalam jumlah yang relatif kecil dilakukan dengan menggunakan kas kecil. Akan tetapi tidak demikian dengan RSU Shanti Graha, selain dana kas kecil juga terdapat kas besar yang digunakan untuk melakukan pembayaran secara tunai dalam jumlah yang relatif besar.

Pada RSU Shanti Graha mekanisme pengelolaan kas kecil yang dilakukan yaitu dengan melakukan metode urgen (mendesak). Metode tersebut dilakukan untuk memenuhi keperluan yang bersifat urgen (mendesak) yang lebih didahulukan dibandingkan dengan keperluan yang bisa di tunda. Hal tersebut bertujuan untuk mengatur pengeluaran dana kas kecil agar lebih efisien dan menghindari munculnya hutang. Pada setiap pengajuan 
mengenai pengeluaran dana kas kecil pada RSU Shanti Graha akan dibentuk cadangan kas kecil, mengingat sewaktu-waktu akan adanya kebutuhan yang mendadak dan mendesak, yang tidak memungkinkan untuk mengambil uang di bank lagi kalau dana kas kecil di kasir sudah habis. Sehingga hal tersebut akan kurang efisien dilakukan jika harus menunggu pengisian kembali dana kas kecil terlebih dahulu.

\section{Kesimpulan dan Saran}

Berdasarkan hasil pembahasan yang dilakukan pada RSU Shanti Graha mengenai sistem pengendalian dan mekanisme pengelolaan kas kecil yang telah diuraikan pada Bab IV, maka dapat ditarik simpulan :

1. Sistem pengendalian intern terhadap kas kecil yang dilakukan pada RSU Shanti Graha belum memadai. Hal tersebut dapat dilihat dari hasil analisis pengendalian terhadap kas kecil RSU Shanti Graha yaitu masih adanya perangkapan tugas antara fungsi kasir dengan fungsi akuntansinya, dimana kasir kas kecil juga bertugas melakukan pencatatan seluruh transaksi kas kecil. Kemudian pada sistem pencatatannya yang menetapkan metode fluktuasi yang menyebabkan catatan akuntansinya tidak dapat direkonsiliasi dengan rekening koran bank secara periodik serta folmulir yang digunakan pun kurang lengkap. Selain dana kas kecil juga terdapat kas besar yang digunakan untuk melakukan pembayaran secara tunai dalam jumlah yang besar dan tidak menggunakan cek, hal tersebut berisiko dalam penggelapan uang yang berpengaruh terhadap dana kas kecil.

2. Pada mekanisme pengelolaan kas kecil pada RSU Shanti Graha belum adanya pengelolaan yang mengkhusus dan menjamin pengelolaan kas kecil yang lebih baik. Metode yang digunakan adalah metode urgen (mendesak), yaitu metode yang lebih mendahulukan kebutuhan yang lebih mendesak dibandingkan kebutuhan yang bisa ditunda, dengan tujuan agar pengeluaran dana kas kecil yang dilakukan lebih efisien. 
Vol. 6, No.2 OKTOBER 2017

p-ISSN : 2337-537X

\section{Daftar Pustaka}

Aris Kurniawan. 2016 "Pengertian Perusahaan Menurut Para Ahli", tersedia pada http://www.gurupendidikan.com/pengertian-perusahaan-menurut-para ahlibesertajenis-unsur-dan-contohnya-lengkap/ 10 Mei 2017

Baridwan,Zaki.1992.Intermediate Accounting.Edisi7.Yogyakarta:BPFE

Erni Sulindawati, N.L.G. 2015. Bahan Ajar Manajemen Keuangan. Singaraja: Undiksha

Erni Sulindawati,N.L.G dkk. 2013. Intermediate Accounting I. Singaraja : Undiksha Press

Ferdinansyah.2007. Ekonomi untuk SMA dan MA kelas XII IPS. Jilid 3. Jakarta : Tropica

Herawati, Trisna.2007. Pengantar Akuntansi I . Undiksha Singaraja

Jelajah Internet. 2015 "Pengertian Laporan Keuangan Menurut Para Ahll", tersedia pada http://www.jelajahinternet.com/2015/10/4-laporan-keuangan-menurut-paraahli.html $\underline{05 \text { April } 2017}$

Jusup, Al. Haryono. 2011. Dasar-dasar Akuntansi. Edisi 7. Jilid 1. Yogyakarta : Bagian Penerbitan Sekolah Tinggi Ilmu Ekonomi YKPN

Kasmir.2008. Analisis Laporan Keuangan. Jakarta: Rajawali Pers

Munawir, S.1999. Analisis Laporan Keuangan.Yogyakarta:Liberty

Mulyadi. 2001. Sistem Akuntansi. Edisi Ketiga. Yogyakarta: STIE YKPN

Novita Pujiantari.2015 "Tugas Akhir". Analisis Sumber dan Penggunaan Modal Kerja Pada LPD Desa Adat Sulanyah Kecamatan Seririt Periode 2012-2014. Singaraja:

Perpustakaan Undiksha

Repository. 2012 "Pengertian Rumah Sakit", tersedia pada http://repository.usu.ac.id/bitstream/handle/123456789/25391/Chapter\%20Il.pdf;jses sionid=7D1417BE2E89F8FA989374CA923A0183?sequence=4, 04 April 2017

Roman Nurbawa.2015 "Pengertian Laporan Keuangan", tersedia pada https://romannurbawastore.wordpress.com/2012/05/06/pengertian-laporan keuangan-menurut-pakar-ahlinya/, 05 April 2017

RSU Shanti Graha. 2016 "Sejarah RSU Shanti Graha”, tersedia pada http://listrumahsakit.com/informasi-rsu-shanti-graha/dan http://rsushantigraha.com/sejarah/, 05 April 2017

Soemarso SR. 1992. Akuntansi Suatu Pengantar. Edisi keempat. Jakarta: Rineka Cipta. 